\title{
To Reviews on Physiological and Pathological Roles of Cell Death
}

\author{
Shin Yonehara \\ Graduate School of Biostudies and Institute for Virus Research, Kyoto University, Kawaharacho, Shogoin, \\ Sakyo-ku, Kyoto 606-8507, Japan
}

Correct cell number is maintained by a balance of two physiological processes: cell growth (mitosis) and cell death (apoptosis/programmed cell death). Until 15 or so years ago, the efforts of the biological scientists were focused almost exclusively on analysis of the cell cycle, with cell death being failed to notice. John F. Kerr had studied the process of shrinkage necrosis, which was renamed "apoptosis" by him along with Andrew H. Wyllie and Alistair R. Currie in 1972 to distinguish this active process from necrosis (Kerr et al., 1972). Since the late 1980s, the importance of apoptosis has become more widely appreciated, and the cell and molecular biology of apoptosis has been studied in great detail in a number of invertebrate and vertebrate model systems.

H. Robert Horvitz scrutinized the genetics of developmental cell death in the nematode Caenorhabditis elegans. These deaths show many similarities to mammalian apoptosis, but also some differences (Hengartner, 2000). Mutant C. elegans strains with abnormal developmental death were shown to result from mutations in several genes, indicating that these cell deaths are genetically controlled. Two of these genes (ced-3 and ced-4) are necessary for cell death, while another (ced-9) is required for survival. All of these genes have been shown to have structural and functional mammalian homologues, revealing the common generic character of death pathways in animal cells.

In 1988, David L. Vaux, Suzanne Cory and Jerry M. Adams reported that the principal function of the protooncogene Bcl-2, which had been cloned by Yoshihide Tsujimoto (Tsujimoto et al., 1984), is to prevent cell death (Vaux et al., 1988). In 1994, Michael O. Hengartner and H. Robert Horvitz revealed striking results indicating that Bcl-2 is the mammalian homologue of ced-9 (Hengartner and Horvitz, 1994). Bcl-2 was then regarded to be the prototype of a family of genes that influence cell survival by their interactions with death effectors.

Junying Yuan and $\mathrm{H}$. Robert Horvitz revealed that CED-3 is the cysteine protease cleaving substrates preferentially at aspartates, and demonstrated the sequence identity between

Graduate School of Biostudies and Institute for Virus Research, Kyoto University, Kawaharacho, Shogoin, Sakyo-ku, Kyoto 606-8507, Japan.

Tel: +81-75-751-4783, Fax: +81-75-751-4784

E-mail: syonehar@virus.kyoto-u.ac.jp
CED-3 and mammalian interleukin-1-converting enzyme (ICE or caspase-1) (Yuan et al., 1993). In addition, Masayuki Miura and Junying Yuan showed induction of apoptosis in mammalian cells by not only ICE/caspase-1 but also CED-3 (Miura et al., 1993). Thereafter, it became clear that the mammalian homologues of CED-3 comprise a family of cysteine proteases, known now as caspases. These cleave next to an aspartate residue and exist as inactive pro-enzymes that are themselves activated by cleavage.

In 1997, the hitherto missing mammalian homologue of CED-4 was identified by Hua Zou and Xiaodong Wang, and turned out to be a mitochondrial protein, apoptosis-activating factor-1 (Apaf-1) (Zou et al., 1997). The mammalian Apaf-1 pathway arises in stressed mitochondria. The decision to irreversibly commit to apoptosis is made at the mitochondrial surface in a series of interactions between antiapoptotic and pro-apoptotic Bcl2-family proteins (Ranger et $a l .$, 2001). Although the details of these processes are still elusive, changes in membrane permeability lead to release of mitochondrial pro-apoptotic factors such as cytochrome c. The released cytochrome c activates Apaf-1-associated caspase- 9 through binding directly to Apaf-1.

Another early milestone was the discovery of a mammalian-specific signaling pathway for the activation of apoptosis in lymphocytes and other cells. This pathway is mediated by cell-surface receptor, discovered independently by my and Peter Krammer's laboratories by screening of panels of monoclonal antibodies for human cell surface components. Peter H. Krammer and myself independently designated the apoptosis-inducing cell-surface receptor as APO-1 and Fas, respectively. In May 1989, we reported anti-Fas monoclonal antibody with associated cell-killing activity (Yonehara et al., 1989) and Krammer's group reported APO-1 in July 1989 (Trauth et al., 1989). Fas turns out to be a member of the superfamily of receptors for tumor necrosis factor (Itoh et al., 1991), and its potential in immune regulation and tumor therapy were recognized (Trauth et al., 1989; Yonehara, 2002). Lastly, in a triumph of yeast two-hybrid system and microsequencing, a route from Fas to caspase-8 (also known as FLICE) through a set of rapidly recruited cytosolic proteins, including at least adaptor protein FADD and caspase-8, was identified (Ashkenazi and Dixit, 1998; Wallach et al., 1999). 
Although data are emerging on how apoptosis is triggered, it will be important to learn how to utilize the information to better understand the role of these mechanisms in normal development and disease (the physiological and pathological roles of apoptosis/cell death). The topics to be covered in this series of reviews include the generation and characterization of knockout mice of key molecular players in apoptosis, and discussions of specific apoptotic mechanisms in the context of organismal physiology. This will provide an outstanding opportunity to obtain up to date information on the complex molecular mechanisms involved in apoptosis without losing sight of the physiological role of apoptosis in homeostasis and the pathological consequences of disruptions to the apoptotic program.

\section{References}

Ashkenazi, A. and Dixit ,V.M. 1998. Death receptors: signaling and modulation. Science, 281: 1305-1308.

Hengartner, M.O. and Horvitz, H.R. 1994. C. elegans cell survival gene ced-9 encodes a functional homolog of the mammalian proto-oncogene bcl-2. Cell, 76: 665-676.

Hengartner, M.O. 2000. The biochemistry of apoptosis. Nature, 407: 770776.

Itoh, N., Yonehara, S., Ishii, A., Yonehara, M., Mizushima, S., Sameshima, M., Hase, A., Seto, Y., and Nagata, S. 1991. The polypeptide encoded by the cDNA for human cell surface antigen Fas can mediate apoptosis. Cell, 66: 233-243.

Kerr, J.F., Wyllie, A.H., and Currie, A.R. 1972. Apoptosis: a basic biological phenomenon with wide-ranging implications in tissue kinetics. $B r . J$.
Cancer, 26: 239-257.

Miura, M., Zhu, H., Rotello, R., Hartwieg, E.A., and Yuan, J. 1993. Induction of apoptosis in fibroblasts by IL-1 beta-converting enzyme, a mammalian homolog of the C. elegans cell death gene ced-3. Cell, 75: 653660.

Ranger, A.M., Malynn, B.A., and Korsmeyer, S.J. 2001. Mouse models of cell death. Nat. Genet., 28: 113-118.

Trauth, B.C., Klas, C., Peters, A.M., Matzku, S., Moller, P., Falk, W., Debatin, K.M., and Krammer, P.H. 1989. Monoclonal antibodymediated tumor regression by induction of apoptosis. Science, 245: 301305.

Tsujimoto, Y., Finger, L.R., Yunis, J., Nowell, P.C., and Croce, C.M. 1984. Cloning of the chromosome breakpoint of neoplastic B cells with the $\mathrm{t}(14 ; 18)$ chromosome translocation. Science, 226: 1097-1099.

Vaux, D.L., Cory, S., and Adams, J.M. 1988. Bcl-2 gene promotes haemopoietic cell survival and cooperates with c-myc to immortalize pre-B cells. Nature, 335: 440-442.

Wallach, D,. Varfolomeev, E.E., Malinin, N.L., Goltsev, Y.V., Kovalenko, A.V., and Boldin, M.P. 1999. Tumor necrosis factor receptor and Fas signaling mechanisms. Annu. Rev. Immunol., 17: 331-367.

Yonehara, S., Ishii, A., and Yonehara, M. 1989. A cell-killing monoclonal antibody (anti-Fas) to a cell surface antigen co-downregulated with the receptor of tumor necrosis factor. J. Exp. Med., 169: 1747-1756.

Yonehara, S. 2002. Death receptor Fas and autoimmune disease: from the original generation to therapeutic application of agonistic anti-Fas monoclonal antibody. Cytokine Growth Factor Rev., 13: 393-402.

Yuan, J., Shaham, S., Ledoux, S., Ellis, H.M., and Horvitz, H.R. 1993. The C. elegans cell death gene ced-3 encodes a protein similar to mammalian interleukin-1 beta-converting enzyme. Cell, 75: 641-652.

Zou, H., Henzel, W.J., Liu, X., Lutschg, A., and Wang, X. 1997. Apaf-1, a human protein homologous to $C$. elegans CED-4, participates in cytochrome c-dependent activation of caspase-3. Cell, 90: 405-413. 